\title{
Coronary collaterals reduce microvascular obstruction and improve long-term survival in patients with ST-segment elevation myocardial infarction treated by primary coronary intervention Steffen Desch*, Ingo Eitel, Gerhard Schuler and Holger Thiele
}

\begin{abstract}
Address: University of Leipzig - Heart Center, Leipzig, Germany
\end{abstract}
* Corresponding author

from 13th Annual SCMR Scientific Sessions

Phoenix, AZ, USA. $21-24$ January 2010

Published: 21 January 2010

Journal of Cardiovascular Magnetic Resonance 2010, I2(Suppl I):P203 doi:I0.I I86/I532-429X-I2-SI-P203

This abstract is available from: http://jcmr-online.com/content//2/SI/P203

(C) 2010 Desch et al; licensee BioMed Central Ltd.

\section{Introduction}

There is inconsistent data regarding the role of coronary collateral flow prior to reperfusion in patients with acute ST-segment elevation myocardial infarction (STEMI). We sought to determine whether the presence of angiographically visible collaterals is associated with beneficial effects on clinical prognosis, infarct size and microvascular obstruction as measured by cardiac magnetic resonance imaging (MRI) in patients with acute STEMI treated by primary percutaneous coronary intervention (PCI).

\section{Methods}

We examined 235 patients with STEMI undergoing primary PCI within $12 \mathrm{~h}$ after symptom onset. All patients exhibited Thrombolysis In Myocardial Infarction (TIMI) flow grades 0 and 1 precluding sufficient antegrade flow in the infarct-related artery (IRA). Collateral flow to the IRA was graded according to the Rentrop-classification: Grade 0: no visible filling of any collateral channel; grade 1: filling of the side branches of the IRA; grade 2: partial filling of the epicardial vessel of the IRA; grade 3: complete collateral filling of the epicardial vessel. Patients were divided in 2 groups according to the extent of collateral flow (group A: Rentrop grades 0 and 1; group B: Rentrop grades 2 and 3). In total, 204 patients (87\%) underwent contrast-enhanced cardiac MRI within 1-4 days using a $1.5 \mathrm{~T}$ MRI scanner to determine infarct size and extent of microvascular obstruction (MO) measured 1 and 15 minutes after contrast injection.

\section{Results}

Altogether, $166(71 \%)$ of patients displayed absent or weak collateral flow to the IRA (group A), 69 (29\%) had significant collateral flow (group B). As compared to group $\mathrm{A}$, the extent of microvascular obstruction was significantly reduced in group B at early MRI imaging (3.3\% $\mathrm{LV}$; interquartile range [IQR] 1.0 to 6.1 versus $2.1 \% \mathrm{LV}$; IQR 0.4 to $4.1, \mathrm{p}=0.009)$ and showed a strong trend at late imaging ( $0.9 \% \mathrm{LV}$; IQR 0.2 to 2.4 versus $0.7 \% \mathrm{LV}$; IQR 0.0 to $1.7, \mathrm{p}=0.08)$. There were no significant differences with regard to infarct size (22.5\% LV; IQR 11.4 to 31.5 versus $18.8 \% \mathrm{LV}$; IQR 10.8 to $29.6, \mathrm{p}=0.20$ ).

Clinical outcome at a median follow-up of 1.7 years (IQR 1.0 to 2.8 ) showed improved survival in group $\mathrm{B}(\mathrm{p}=$ $0.041)$.

\section{Conclusion}

The presence of a well-developed collateral network prior to reperfusion by PCI in patients with acute STEMI is associated with reduced long-term mortality which might in part be explained by a protective effect on the coronary microcirculation. 